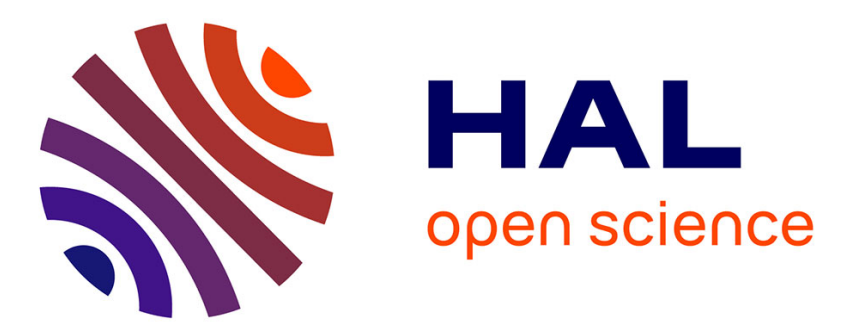

\title{
High cycle fatigue damage evaluation of steel pipelines based on microhardness changes during cyclic loads
}

Geovana Drumond, Francine Roudet, I. Pasqualino, B. Pinheiro, Didier Chicot, Xavier Decoopman

\section{- To cite this version:}

Geovana Drumond, Francine Roudet, I. Pasqualino, B. Pinheiro, Didier Chicot, et al.. High cycle fatigue damage evaluation of steel pipelines based on microhardness changes during cyclic loads. CFM 2017 - 23ème Congrès Français de Mécanique, Aug 2017, Lille, France. hal-03465775

\author{
HAL Id: hal-03465775 \\ https://hal.science/hal-03465775
}

Submitted on 3 Dec 2021

HAL is a multi-disciplinary open access archive for the deposit and dissemination of scientific research documents, whether they are published or not. The documents may come from teaching and research institutions in France or abroad, or from public or private research centers.
L'archive ouverte pluridisciplinaire HAL, est destinée au dépôt et à la diffusion de documents scientifiques de niveau recherche, publiés ou non, émanant des établissements d'enseignement et de recherche français ou étrangers, des laboratoires publics ou privés. 


\title{
High cycle fatigue damage evaluation of steel pipelines based on microhardness changes during cyclic loads
}

 \\ a. Subsea Technology Laboratory (LTS), POBox 68508, CEP 21945-970 RIO DE JANEIRO (BRAZIL) \\ b. Laboratoire de Mécanique de Lille (LML-FRE 3723), bd Paul Langevin, 59655 VILLENEUVE D’ASCQ
}

\begin{abstract}
:
The aim of this work is to investigate changes in material surface microhardness during the different stages of fatigue life. Samples of API 5LX65 grade steel were submitted to high cycle fatigue tests in which different stages of microhardness changes are observed and then correlated to those observed by TEM images.
\end{abstract}

Key words: Pipelines; Steel; High cycle fatigue; Fatigue damage, Microhardness.

\section{Introduction}

The phenomenon of metal fatigue has a complex nature involving several stages. The main stages identified are microcrack initiation and propagation until the final fracture. Surface effects are of particular importance for the fatigue phenomenon, since in most cases the surface is the preferred site for nucleation of microcracks due to easier slip movements and higher strain amplitudes at the surface. According to Ye and Wang [1], a great deal of experimental evidence has proved that fatigue damage in the stages prior to nucleation of microcracks is primarily related to the occurrence and development of localized plastic-strain concentration at or near the surface of materials during cycling. So, the resistance to microplastic deformation on the surface should reflect the fatigue damage resistance. Indeed, the hardness of a material shows its ability to resist microplastic deformation caused by indentation or penetration and is closely related to the plastic slip capacity of the material. Therefore, it is significant to study the resistance to microplastic deformations based on microhardness changes on the surface, and the associated accumulation of fatigue damage. This method of studying fatigue damage has fundamental importance in the search for a new way to predict fatigue life of metal structures under service conditions before macroscopic cracking.

\section{Literature Review}

Several authors used microhardness testing as a mean of predicting fatigue damage of metal specimens. In 1996, Ye et al. [2] measured the Vickers hardness of ferrite and pearlite at the surface of an annealed $0.46 \%$ carbon steel sample during different numbers of cycles under high cycle fatigue. The authors observed that the hardness variation versus the number of cycles was characterized by three periods, related to hardness increasing (cyclic hardening effect), stabilizing and decreasing (softening effect). 
Ye et al. [3] performed a deeper investigation in fatigue hardening/softening behavior through Vickers hardness measurements related to changes of micromechanical properties during high cycle fatigue. The author showed that it is possible to detect fatigue hardening/softening of a metal by measurement of the post-cycled tensile curves. Aiming to write an expression that correlates the total deformation experienced by the samples and the hardness measurements obtained in Vickers hardness tests, Ye et al. [3] did some assumptions and derivations based on the geometric scheme of the indenter and obtained an expression for total deformation as follows (Eq.1):

$$
\varepsilon^{H}=\ln (\sin \alpha)=\varepsilon_{e}^{H}+\varepsilon_{p}^{H}\left[-\frac{H \nu}{E \sin \alpha\left(1-v+2 v^{2}\right)}\right]+\varepsilon_{p}^{H}
$$

where $\alpha$ is the angle between the surface profile after and before loading, $E$ the Young's modulus and $v$ the Poisson's ratio. The presence of the material constants $E$ and $v$ in this expression results from the generalized Hooke's law. Complete calculus is described in [3].

Still in the theme of hardness measurement during cyclic loading aiming the analysis of fatigue behavior of steel samples, Ye and Wang [1] introduced the concept of continuum damage mechanics (CDM). The authors proposed a variable describing pre-nucleation fatigue damage with the objective of studying a new approach for non-destructive inspection of fatigue damage, especially at their early stages occurring in engineering components under service conditions. Based on experimental evidences and using concepts of stress-strain already widely regarded in the literature, Ye and Wang [1] obtained a mathematical relation of the hardness (HD) with damage variable (D) for a damage material (Eq.2):

$$
H_{D}=C(1-D) k\left(\varepsilon+\varepsilon_{H}\right)^{m}
$$

where $C$ is a proportionality constant that takes different values depending on the type of indenter used, $D$ is the damage variable representing the deterioration of the material's properties and microstructures under the loading of external forces, $k$ and $m$ are material constants, $\varepsilon$ is the plastic natural strain, and $\varepsilon_{H}$ is the strain introduced by the hardness test itself within the indentation plastically deformed zone ( $\varepsilon_{H}$ is approximately 0.08 in the case of Vickers indentation).

In terms of the variation of hardness for the isotropic damage case, damage variable $(D)$ can be evaluated as (Eq.3):

$$
D=1-\frac{H_{D}}{H}
$$

where $H_{D}$ and $H$ are the hardness of a damaged material and a non-damaged material, respectively.

\section{Material properties characterization}

Uniaxial tension tests were carried out to evaluate relevant mechanical properties of the API 5L X65 grade steel. Six tension test specimens were machined in the longitudinal direction of the pipe sample (Figure 1). Tensile tests were carried in an INSTRON (8802) universal testing machine equipped with a $10 \mathrm{kN}$ load cell. Tests were carried with a strain rate of $2.64 \times 10^{-4} \mathrm{~m} / \mathrm{m} \mathrm{s}^{-1}$, at room temperature, according to specifications of ASTM E8M-04 standard [4]. The strains were measured with the aid of a clip gage. Table 1 presents average mechanical properties obtained. 


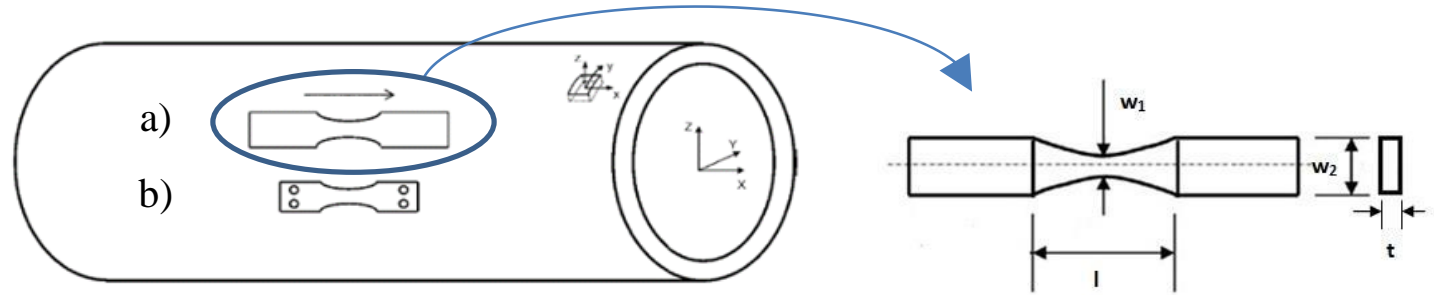

Figure 1: Samples cut off from API 5L X65 grade steel pipe for: (a) tensile tests, where $w_{1}=20 \mathrm{~mm}$, $w_{2}=30 \mathrm{~mm}, l=40 \mathrm{~mm}$, and $t=3 \mathrm{~mm}$; and (b) fatigue tests.

Table 1: Average mechanical properties for API 5 L X65 grade steel.

\begin{tabular}{cccccc}
\hline & $\begin{array}{c}\text { Young modulus } \\
(\mathrm{GPa})\end{array}$ & $\begin{array}{c}\text { Yield strength } \\
(\mathrm{MPa})\end{array}$ & $\begin{array}{c}\text { Proportional } \\
\text { limit }(\mathrm{MPa})^{*}\end{array}$ & $\begin{array}{c}\text { Ultimate tensile } \\
\text { strength }(\mathrm{MPa})\end{array}$ & $\begin{array}{c}\text { Ultimate tensile } \\
\text { strain }(\%)\end{array}$ \\
\hline Average & $\mathbf{2 1 1} \pm \mathbf{5}$ & $\mathbf{4 2 1} \pm \mathbf{8}$ & $\mathbf{3 6 9} \pm \mathbf{4 5}$ & $\mathbf{5 1 7} \pm \mathbf{7}$ & $\mathbf{5} \pm \mathbf{0 . 3}$ \\
\hline
\end{tabular}

*Proportional limit is the maximum stress before material yielding

\subsection{Fatigue tests}

Fatigue tests were performed in a Schenck machine model PWON [5]. Samples were submitted to room temperature high cycle fatigue $(\mathrm{HCF})$ tests under strain-controlled alternating bending loadings (sinusoidal waveform) at a frequency of $25 \mathrm{~Hz}$.

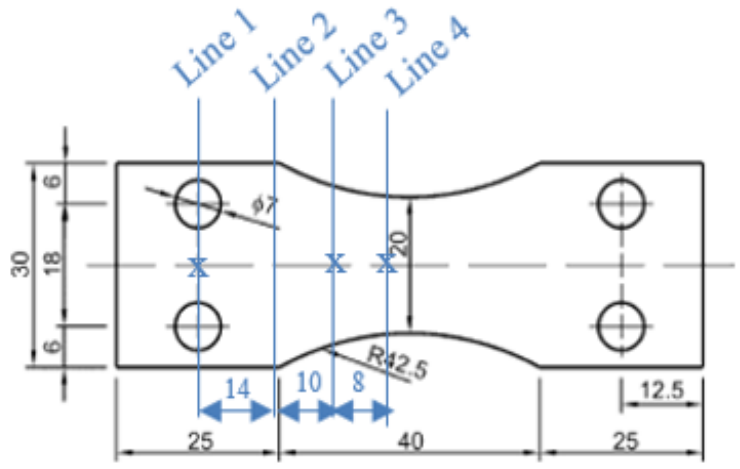

Figure 2: Fatigue samples (dimensions in millimeters).

Fatigue samples were machined from the same pipe used to produce the tensile samples (Figure 1). The geometry and dimensions of the fatigue samples are depicted in Figure 2. Samples were submitted to electrolytic polishing using a perchloric-based acid solution (standard electrolyte Struers A2) to reduce the surface roughness, which could affect indentation measurements. From tensile properties obtained for API 5L X65 grade steel and assuming the surface condition factor $\mathrm{k}_{\mathrm{a}}$ as 0.91705 (grinding surface finish) [5], an endurance limit $S_{e}$ of $270 \mathrm{MPa}$ was estimated for fatigue test samples. The Basquin equation, which relates the number of stress cycles to failure $(\mathrm{N})$ to the alternating stress $(\mathrm{Sn})$, was calculated as follows (Eq. 4):

$$
\mathrm{Sn}=872.1 \mathrm{~N}^{-0.0953}
$$




\subsection{Indentation tests}

Aiming to study the fatigue damage accumulated in the microstructure of the samples, Berkovich microhardness tests were carried out in the samples previously submitted to HCF tests. Instrumented indentation tests (IIT) have been performed using a CSM 2-107 microhardness tester. Berkovich indenter was used for each sample analysis with maximum loads ranging from 0.2 to $2 \mathrm{~N}$. A dwell-time of $15 \mathrm{~s}$ was imposed at the maximum applied load, and loading and unloading rates have been set up at $100 \mathrm{mN} / \mathrm{min}$. The load resolution is $100 \mu \mathrm{N}$ and the depth resolution is $0.3 \mathrm{~nm}$ (provided by the CSM Instruments Group) [6]. Berkovich indentations were done in 3 different points of the sample, which are represented as $x$ in Figure 2. For each point, the machine performed 20 indentation cycles at the same location using a progressive loading protocol between $P_{\min }=200 \mathrm{mN}$ and $P_{\max }=2,000 \mathrm{mN}$.

According to N'Jock et al. [7], during indentation tests, the material can flow under the indenter by two different modes of deformation: sinking-in, when the material is pulled down toward the tip of the indent, or piling-up, when the material is pushed away from the center of the indent. Consequently, corrections proposed by Oliver and Pharr [8] for sinking-in and Loubet et al. [9] for piling-up should be made, in addition to other corrections associated with the indenter tip defect as well as the compliance of the instrument. Still following N'Jock et al. [7], the authors presented a criterion to determine the predominant deformation mode. According to them, for materials for which the ratio between the residual indentation depth and the maximum indentation depth reached at the maximum load is higher than 0.83 , piling-up prevails, while sinking-in is observed when this ratio is lower than 0.83 .

From IIT measurements leading to a load $(P)$ - indenter displacement $(h)$ curve, the hardness $H$ is defined as the ratio between the maximum load $\left(P_{\max }\right)$ and the projected contact area $\left(A_{c}\right)(\mathrm{Eq} .5)$ :

$$
H=\frac{P_{\max }}{A_{c}}
$$

The projected contact area $\left(A_{c}\right)$ is a parameter of fundamental importance to the material hardness computation, but its calculation is not trivial. For the two different modes of deformation (sinking-in and piling-up), Oliver and Pharr [8] and Loubet et al. [9] expressed the contact area $A_{c}$ by different expressions. In this work, the results comprise ratios between the residual indentation depth and the maximum indentation depth higher than 0.83, and because of that, Loubet et al. [9] equation was used (Eq.6):

$$
A_{c_{L A}}=24.56 \alpha^{2}\left(h_{\max }-\frac{P_{\max }}{S}+h_{b}\right)^{2}
$$

where $h_{\max }$ is the maximum indentation depth, $S$ the elastic unloading stiffness, $\alpha$ a constant equal to 1.2 , and $h_{b}$ the truncation length of the tip defect.

\section{$4 \quad$ Results and discussion}

Fatigue bending tests were conducted under a strain amplitude of $1.7 \%$, corresponding to an alternating stress amplitude $\left(\sigma_{a}\right)$ of $358 \mathrm{MPa}$ at the sample center (20 mm width), with stress ratios $R$ around -1 (fully reversed stress). For this stress amplitude, one sample (T2EF08) was cycled up to failure, giving 
a fatigue life of 30,100 cycles. In addition, the samples T2EF09, T2EF10 and T2EF11 were fatigue cycled up to $25 \%, 50 \%$ and $75 \%$ of the fatigue life, respectively. Then, indentation tests were performed to evaluate hardness changes and fatigue damage accumulation at these four different stages of fatigue life

Due to the specimen positioning in the fatigue machine, an encastrer condition is produced at line 1 (Figure 2), i.e. no cyclic loading is applied at this region. Thus, the hardness calculation in line 1 is taken as the reference hardness value $\left(H_{0}\right)$ for the sample. The smaller width in the center of the sample leads to the highest stress amplitude in this region, in which the rupture ends up. Lines positioned away from the sample center undergo lower stress amplitudes, due to width increase, resulting in stress amplitudes of 335 and $225 \mathrm{MPa}$ at lines 4 and 3, respectively. The hardness variations before and after fatigue cycling were evaluated based on the difference between hardness values of lines 3 and $4\left(\mathrm{H}_{3}\right.$ and $H_{4}$, respectively) with respect to line $1\left(H_{0}\right)$.

Figure 3(a) and (b) show the evolution of the hardness values in relation to the fatigue life of the material for the values measured in line 3 and line 4, respectively. Figure 3 shows three successive stages, concerning a decrease in hardness values until $50 \%$ of the fatigue life of the material, followed by an increase from 50 to $75 \%$ of the fatigue life, and the last stage of sharp decrease in hardness values. It is supposed that a connection could exist between them and the four phases of fatigue damage mechanisms, which can be identified as microcrack initiation (nucleation), microcracking, macrocrack propagation, and final fracture.

(a)

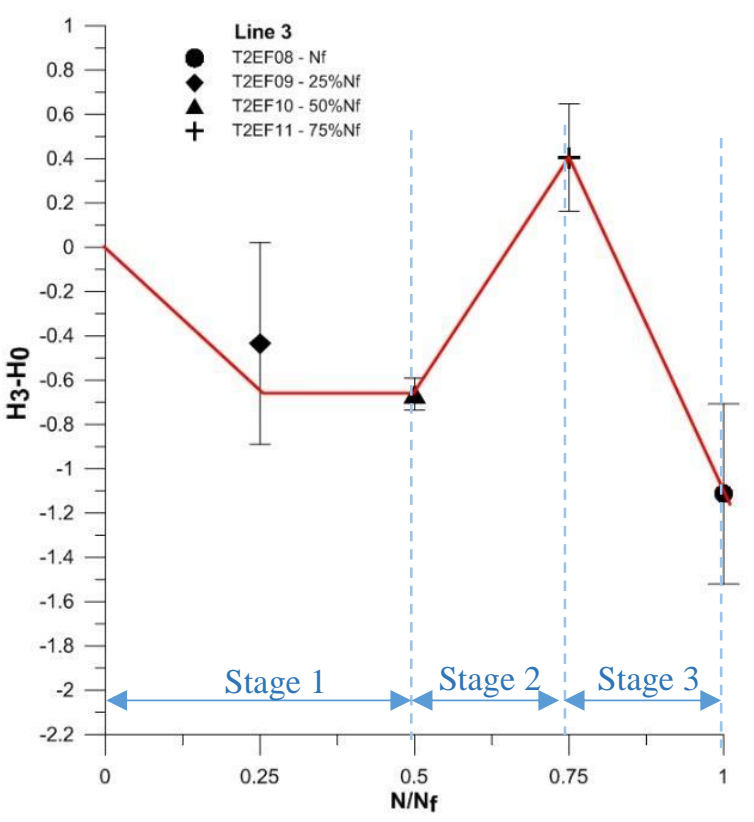

(b)

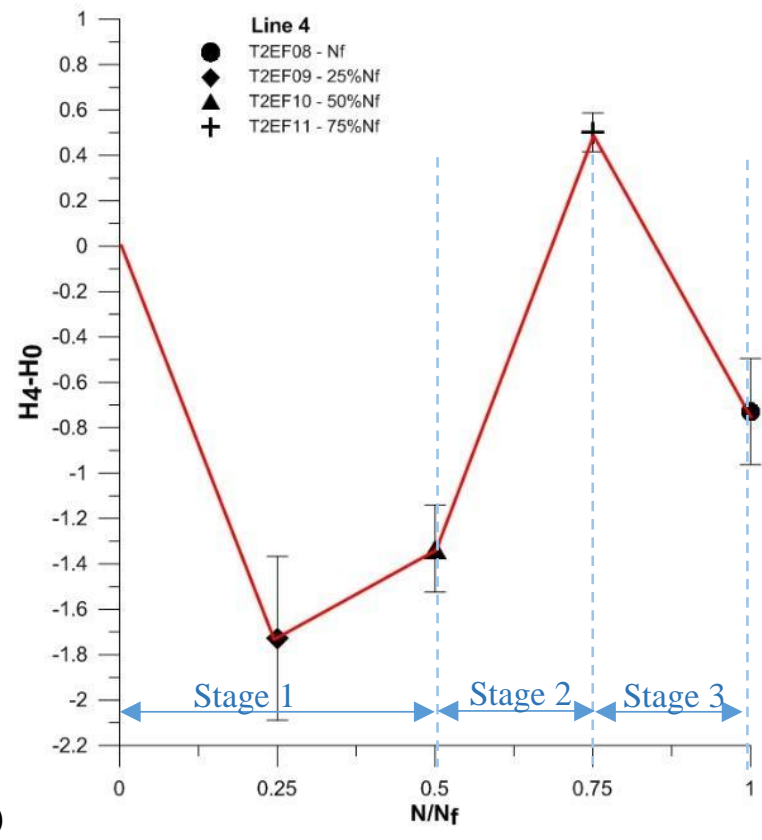

Figure 3: Evolution of hardness values during fatigue life for (a) line 3 and (b) line 4 measurements.

In Stage 1, the hardness decrease can be associated with the movement and multiplication of dislocations and rearrangement of the initial dislocation network. Part of the initial dislocation network 
is produced during the pipe manufacturing process by cold working. Sample preparation (machining, grinding and polishing), which is also likely to induce some level of residual stresses, may also influence the initial dislocation arrangement [10]. At the early stages of fatigue, microstructural changes related to the movement and reorganization of dislocations are expected, leading to a reduction of microdeformations and consequently, a softening behavior of the material. In Stage 2, the hardness increase could be related to the process of microcracks initiation and propagation. The multiplication of dislocations and microdeformations can be associated with material hardening. In Stage 3, hardness decrease (softening) could be attributed to the relaxation of microstresses due to macrocrack initiation and propagation, preceding final failure. Further analyses will include macrocrack observations.

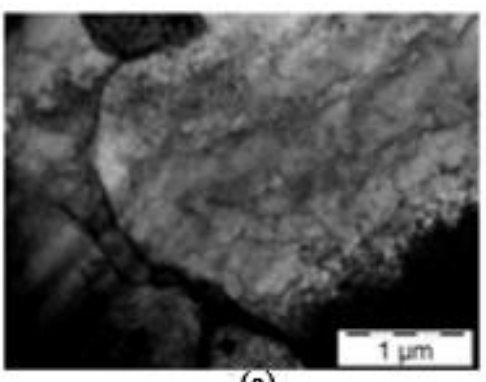

(a)

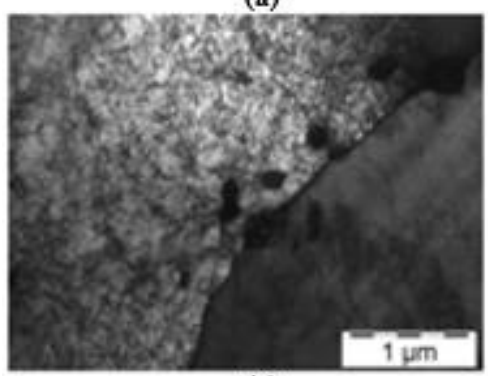

(c)

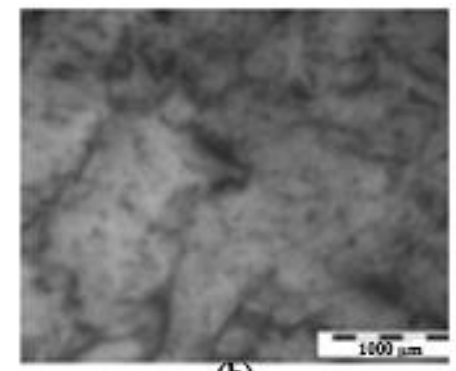

(b)

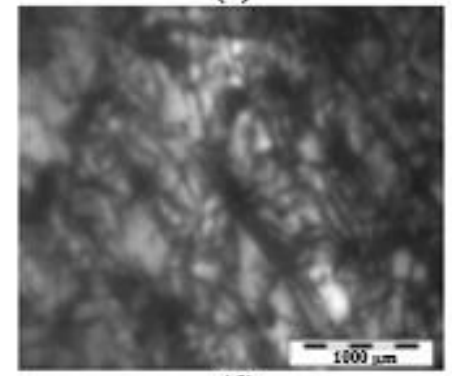

(d)

Figure 4: Dislocation network obtained by TEM from specimens fatigued with an applied alternating stress of $319 \mathrm{MPa}(R=-1)$ to (a)-(b) 20.000 cycles and(c)-(d) 120.000 cycles [3].

In a previous work [11], transmission electron microscopic (TEM) images for a similar material (API X60 steel) also showed different stages of changes in the microstructural and they are correlated to those observed by indentation. Figures 4 (a)-(b) and (c)-(d) present TEM images obtained from analyses of lamellae produced from API X60 steel samples fatigued to 20,000 and 120,000 cycles, respectively. According to Pinheiro [11], a qualitative evaluation of dislocation structures observed in these images suggests that the dislocation density increased between 20,000 and 120,000 cycles. From comparison of images from Figures 4 (a)-(b) and (c)-(d), it is possible to observe the fatigue damage effect, considering how nested and close to each other are dislocations in Figures 4 (c)-(d), fatigued to 120,000 cycles, with respect to Figures 4 (a)-(b), fatigued to 20,000 cycles [3]. This multiplication of dislocations and increase in microdeformations was equally observed in the Stage 2 of the hardness variation (Figure $3)$. 


\section{Conclusions}

The aim of this ongoing work is to evaluate fatigue damage of pipeline steels through microhardness testing. Different stages of changes in microhardness are found and they are correlated to those observed with transmission electron microscopic (TEM) images from experimental tests performed with a similar material. This correlation could help to corroborate the X-ray diffraction results obtained in a previous work [11] and then, recommend this non-destructive technique as the base of the method for predicting fatigue life of steel structures. Further experimental tests are being carried out in this ongoing work. The obtained results will be considered in the proposal of a new methodology to predict fatigue life of metal structures under service conditions before macroscopic cracking.

\section{Acknowledgments}

The authors would like to thank CAPES (Coordination for the Improvement of Higher Education Personnel) for the financial support.

\section{$7 \quad$ References}

[1] Ye D., Wang Z. (2001). An approach to investigate pre-nucleation fatigue damage of cyclically loaded metals using Vickers microhardness tests. International journal of fatigue, 23(1), 85-91.

[2] Ye D.Y., Wang D.J., An P. (1996). Characteristics of the change in the surface microhardness during high cycle fatigue damage. Materials chemistry and physics, 44(2), 179-181.

[3] Ye D., Tong X., Yao L., Yin X. (1998). Fatigue hardening/softening behaviour investigated through Vickers microhardness measurement during high- cycle fatigue. Materials chemistry and physics, 56(3), 199-204.

[4] American Association of State Highway and Transportation Officials, \& American Society for Testing and Materials. (2004). E8M-04 Standard Test Methods for Tension Testing of Metallic Materials (Metric) 1. ASTM International.

[5] Schenck C., Wechselbiegemaschine PWON, Maschinenfabrik GmbH, Darmstadt, Germany, 1971.

[6] Chicot D., Tilkin K., Jankowski K., Wymysłowski A. (2013). Reliability analysis of solder joints due to creep and fatigue in microelectronic packaging using microindentation technique. Microelectronics Reliability, 53(5), 761-766.

[7] N'jock M.Y., Chicot D., Ndjaka J.M., Lesage J., Decoopman X., Roudet F., Mejias A. (2015). A criterion to identify sinking-in and piling-up in indentation of materials. International Journal of Mechanical Sciences, 90, 145-150.

[8] Oliver W.C., Pharr G.M. (1992). An improved technique for determining hardness and elastic modulus using load and displacement sensing indentation experiments. Journal of Material Research, 7(6), 1564-1583.

[9] Loubet J.L., Bauer M., Tonck A., Bec S., Gauthier B. (1993). Manuel, Mechanical properties and deformation behaviour of materials having ultra-fine microstructures. NATO ASI, 233, 429-447.

[10]Pinheiro B., Lesage J., Pasqualino I., Benseddiq N., Bemporad E. (2012). X-ray diffraction study 
of microstructural changes during fatigue damage initiation in steel pipes. Materials Science and Engineering: A, 532, 158-166.

[11]Pinheiro B. (2011). Étude par diffraction des rayons $X$ des modifications microstructurales en cours de fatigue (Doctoral dissertation, Lille 1). 